\title{
Pó-de-basalto no desenvolvimento de plantas de alface e na dinâmica populacional de insetos
}

Powder-basalt in the development of lettuce plants and population dynamics of insects

\author{
Mártin Zanchett Groth, Cristiano Bellé*, Daniel Bernardi e Raul da Cunha Borges Filho
}

Submissão: 13/05/2016 / Aceite: 31/05/2017

\section{RESUMO}

O objetivo deste trabalho foi avaliar o efeito da aplicação de pó-de-basalto de três origens diferentes, via aplicação no solo (incorporação) e aérea (pulverização) no desempenho de plantas de alface e na dinâmica populacional de insetos fitófagos, respectivamente. Mudas de alface cv. Verônica com oito dias após a emergência foram transplantadas para canteiros após a incorporação dos pós-de-basalto. Os efeitos no desenvolvimento de plantas foram avaliados 50 dias após o transplante, e os parâmetros avaliados foram: estatura de planta, crescimento do sistema radicular, massa seca, diâmetro da inserção, volume do sistema radicular, teores de clorofila e carotenoides. A dinâmica populacional de insetos foi realizada após a aplicação de $100 \mathrm{~g}$ de pó-de-basalto diluídos em dois litros de água, através de quatro pulverizações com intervalos de dez dias entre cada. Amostragens foram realizadas diariamente e os insetos capturados foram triados e identificados. Houve um incremento significativo nas variáveis estaturas de planta, crescimento do sistema radicular e massa seca nos tratamentos onde houve incorporação de pó-debasalto no solo em relação ao tratamento controle. Também foi verificado um aumento significativo de 36 e 20\% no teor de clorofila e carotenoides nas folhas de alface, respectivamente. Para o volume e diâmetro da inserção do caule não houve diferença significativa entre os tratamentos. A pulverização aérea em plantas de alface com soluções com pó-de-basalto influenciou diretamente a dinâmica populacional de insetos com uma redução significativa no número de indivíduos amostrados em todos os tratamentos.

PALAVRAS-CHAVE: flutuação populacional, Lactuca sativa, nutrição, silício.

\section{ABSTRACT}

The aim of this work was to evaluate effect of the application of basalt powders from three different origins via soil (incorporation) and aerial (spraying) application in the performance of lettuce plants and in the population dynamics of phytophagous insects, respectively. Lettuce seedlings cv. Verônica at 8 days after emergence were transplanted to raised beds after the incorporation of the basalt powders. The effects on plant development were evaluated 50 days after transplantation and the parameters assessed were: plant height, growth of root system, dry mass, insertion diameter, volume of the root system and chlorophyll and carotenoid contents. Insect population dynamics was performed after the application of $100 \mathrm{~g}$ of basalt powder diluted in two liters of water ( $2 \mathrm{~L} \mathrm{ha}$ ) through four sprayings with intervals of 10 days between each. Sampling was performed daily and the insects collected were separated and identified. There was a significant increase in the variables plant height, growth of root system and dry mass in the treatments with the incorporation of basalt powder in the soil when compared to the control treatment. There was also a significant increase of $36 \%$ and $20 \%$ in the chlorophyll and carotenoid contents in lettuce leaves, respectively. There was no significant difference in the volume of the root system and insertion diameter between the treatments. The aerial spraying on lettuce plants with different basalt powders directly influenced the insect population dynamics with a significant decrease in the number of insects collected in all treatments.

KEYWORDS: population fluctuation, Lactuca sativa, nutrition, silicon.

Universidade Federal de Pelotas, Pelotas, RS, Brasil.

*Autor para correspondência <crbelle@gmail.com> 


\section{INTRODUÇÃO}

A alface (Lactuca sativa L.) é a hortaliça mais consumida no Brasil, sendo cultivada em todas as regiões brasileiras, com destaque para as regiões Sudeste e Sul (RESENDE et al. 2007, SALA \& COSTA 2012, IBGE 2013). Esta cultura é dependente de uma boa nutrição do solo para que ocorra um bom desenvolvimento foliar (GONDIM et al. 2010), sendo muitas vezes necessária a realização de adubação orgânica para dar equilíbrio ao sistema e proporcionar ao solo condições adequadas para um bom desenvolvimento das plantas. Neste contexto, a utilização de pó-de-basalto pode ser realizada para restabelecer o equilíbrio de minerais no solo e renovar solos pobres ou degradados (PRATES et al. 2012, HANISCH et al. 2013). Sendo assim, a aplicação do pó-de-basalto é definida como uma prática agrícola de incorporação de rochas e/ou minerais ao solo, sendo a calagem e a fosfatagem natural casos particulares desta prática (ESCOSTEGUY \& KLAMT 1998).

A utilização de pó-de-basalto como fertilizante e/ou corretivo do solo é uma alternativa para reduzir os custos de produção e romper com a atual dependência de insumos importados como potássio, fósforo e magnésio, sem comprometer a produtividade das lavouras (MELO et al. 2012). O pó-de-basalto, por ser um composto mineral rico em silício, quando aplicado via solo enriquece os compostos constituídos de resíduos orgânicos (PRATES et al. 2010), colabora para a mineralização de solos degradados (THEODORO et al. 2012) e, de acordo com GOMES et al. (2009), o silício pode apresentar efeito no controle de insetos-pragas e doenças, tanto da parte aérea, como de solo. Além disso, o pó-debasalto resiste mais ao intemperismo proporcionando uma liberação gradual de nutrientes, permanecendo por um período maior na solução do solo, assim, suprindo as necessidades da planta ao longo do seu desenvolvimento, contribuindo para um incremente de produtividade da cultura (OSTERROHT 2003, SILVA et al. 2012).

Devido à presença de uma ampla diversidade de substâncias que compõem o pó-de-basalto, tais como, minerais silicatados, cálcio, magnésio, ferro e óxidos de silício, seu uso na planta pode promover um maior crescimento radicular (RESENDE et al. 2002) e no solo, promover uma maior elevação na capacidade de troca de cátions (CTC), devido à formação de minerais de argila (ALMEIDA et al. 2007, SILVA et al. 2012).

A utilização de pó-de-basalto em cultivos agrícolas pode atuar diretamente sobre a dinâmica populacional de insetos (KORNDÖRFER et al. 2004, SILVA et al. 2010). Estudos demonstraram que a utilização de pó-de-basalto rico em silicatos proporcionou níveis baixos de infestações de pragas (SILVA et al. 2010), benefício este diretamente ligado à presença de silício no pó-de-basalto, uma vez que este elemento químico tem capacidade de aumentar a resistência das plantas ao ataque de insetos devido a sua deposição na epiderme vegetal, formando uma barreira mecânica impedindo a mastigação ou a perfuração da epiderme foliar (KORNDÖRFER et al. 2004, NOJOSA et al. 2005, LAING et al. 2006, SILVA et al. 2010).

Portanto, o objetivo com o presente estudo foi avaliar o desenvolvimento de plantas de alface após a incorporação de pó-de-basalto no solo e os efeitos da aplicação aérea de soluções na dinâmica populacional de insetos fitófagos na cultura da alface.

\section{MATERIAL E MÉTODOS}

O experimento foi conduzido durante $\mathrm{o}$ período de setembro a novembro de 2013 no campo experimental da Universidade do Oeste de Santa Catarina. Previamente à instalação dos bioensaios, foi realizada uma análise do solo seguindo as recomendações de adubação e calagem para os Estados do Rio Grande do Sul e de Santa Catarina (CQFS-RS/ SC 2004). Oito amostras de solo foram coletadas em diferentes pontos de amostragem e encaminhadas ao laboratório de análise de solos da UNOESC. Mediante sua análise química foi estimada uma quantidade de duas toneladas de pó-de-basalto por hectare $\left(\mathrm{t} \mathrm{ha}^{-1}\right)$ para suprir as necessidades minerais do solo. Para a testemunha não houve a adição do composto. O póde-basalto foi adquirido em britadores localizados nos municípios de Belmonte, SC (BM), São Miguel do Oeste, SC (SMO) e São José do Cedro, SC (SJC). Mediante análise química dos compostos, foi determinado que os mesmos possuem características químicas distintas (Tabela 1).

\section{Efeitos do pó-de-basalto incorporado ao solo no desenvolvimento de plantas de alface}

Para verificar o efeito da aplicação de diferentes composições de pó-de-basalto no desenvolvimento de plantas de alface foram confeccionados canteiros 
Tabela 1. Caracterização química do pó-de-basalto coletado nos municípios de Belmonte (BM), São Miguel do Oeste (SMO) e São José do Cedro (SJC), em Santa Catarina.

Table 1. Chemical characterization of the powder-basalt collected in the municipalities of Belmonte (BM), São Miguel do Oeste (SMO), and São José do Cedro (SJC) in Santa Catarina state.

\begin{tabular}{lllllllll}
\hline \multirow{2}{*}{ Municípios } & \multicolumn{7}{c}{ Composição química (\%) } \\
\cline { 2 - 9 } & $\mathrm{SiO}_{2}$ & $\mathrm{Fe}_{2} \mathrm{O}_{3}$ & $\mathrm{Al}_{2} \mathrm{O}_{3}$ & $\mathrm{CaO}$ & $\mathrm{MgO}$ & $\mathrm{Na}_{2} \mathrm{O}$ & $\mathrm{K}_{2} \mathrm{O}_{2}$ & $\mathrm{P}_{2} \mathrm{O}_{5}$ \\
\hline $\mathrm{BM}$ & 48,5 & 16,4 & 14,1 & 9,5 & 3,9 & 3,1 & 1,3 & 0,5 \\
$\mathrm{SMO}$ & 45,3 & 16,3 & 14,0 & 11,5 & 5,2 & 2,4 & 0,9 & 0,3 \\
$\mathrm{SJC}$ & 46,7 & 15,8 & 13,4 & 10,0 & 4,3 & 2,8 & 1,0 & 0,4 \\
\hline
\end{tabular}

$\mathrm{SiO}_{2}$ - Dióxido de silício; $\mathrm{Fe}_{2} \mathrm{O}_{3}$ - Óxido de ferro; $\mathrm{Al}_{2} \mathrm{O}_{3}$ - Óxido de alumínio; $\mathrm{CaO}$ - Óxido de cálcio; $\mathrm{MgO}$ - Óxido de magnésio; $\mathrm{Na}_{2} \mathrm{O}$ - Óxido de sódio; $\mathrm{K}_{2} \mathrm{O}$ - Óxido de potássio; $\mathrm{P}_{2} \mathrm{O}_{5}$ - Pentóxido de fósforo.

$\left(1 \mathrm{~m}^{2}\right)(1,0 \mathrm{~m}$ largura $\times 1,0 \mathrm{~m}$ comprimento $\times 0,40$ $\mathrm{m}$ de altura). Após o preparo dos canteiros em área experimental (céu aberto), foi aplicado o equivalente a $2 \mathrm{t} \mathrm{ha}^{-1}$ do pó-de-basalto para cada repetição que compôs o tratamento, sendo que a testemunha foi isenta da aplicação do pó-de-basalto. Após a incorporação do pó-de-basalto no solo foram transplantadas 16 mudas de alface cv. Verônica em cada canteiro. As mudas foram preparadas em bandejas de polipropileno com 288 células contendo substrato vegetal (Multiplant ${ }^{\mathrm{TM}}$ ). Após oito dias da emergência, foram transplantadas para os canteiros com os diferentes tratamentos em um espaçamento de $0,25 \mathrm{~m}$ entre mudas e entre linhas do canteiro. Durante os 50 dias de execução dos experimentos, os canteiros contendo as mudas de alface foram irrigados somente com água destilada, com uma quantidade de $10 \mathrm{~L} \mathrm{~m}^{-2}$, o equivalente a $10 \mathrm{~mm}$ de chuva a cada dois dias, isto é, em intervalos de $48 \mathrm{~h}$.

Decorridos 50 dias após o transplante, os parâmetros avaliados foram: estatura de planta (EP) $(\mathrm{cm})$, comprimento do sistema radicular $(\mathrm{CSR})(\mathrm{cm})$, diâmetro da inserção do caule (DI) $(\mathrm{cm})$, volume $(\mathrm{V})$ $\left(\mathrm{cm}^{3}\right)$, peso de massa seca (PMS) (g), teor de clorofila parcial e total $\left(\mathrm{mg} \mathrm{g}^{-1}\right)$ e carotenoides totais $\left(\mathrm{mg} \mathrm{g}^{-1}\right)$ de acordo com as metodologias propostas por WITHAM et al. (1971) e LICHTENTHALER \& WELLBURN (1983).

\section{Efeito da aplicação aérea de pó-de-basalto na dinâmica populacional de insetos}

Para avaliar o efeito da aplicação aérea de diferentes composições de pó-de-basalto na dinâmica populacional de insetos fitófagos na cultura da alface, foram preparadas soluções através da mistura de 100 gramas de pó-de-basalto por litro de água destilada
$\left(\mathrm{gL}^{-1}\right)$. Posteriormente, com auxílio de um pulverizador costal manual (Jacto PJH) com capacidade de 20 litros, equipado com bico leque (Teejet XR11008VS) foi aplicado um volume de calda de $450 \mathrm{~L} \mathrm{ha}^{-1}$ equivalendo-se ao ponto de escorrimento na folhagem da cultura. Foram realizadas quatro pulverizações sequenciais para cada tratamento (pó-de-basalto) com intervalos de 10 dias para cada aplicação. As aplicações da solução foram realizadas 10, 20, 30 e 40 dias após o transplante das mudas de alface para os canteiros. Como tratamento controle (testemunha) foram utilizados canteiros com mudas de alface pulverizados somente com água. Diariamente, foi avaliada a dinâmica populacional de insetos fitófagos presentes em cada canteiro através de coletas manuais com auxílio de tubos de vidro $(1,5 \mathrm{~cm}$ de diâmetro $\times$ $8,0 \mathrm{~cm}$ de comprimento) durante 50 dias. Os insetos capturados foram armazenados em sacos plásticos (3 litros) e levados ao laboratório para a triagem e contagem das espécies coletadas, sendo a identificação realizada com auxílio de chave dicotômica e manuais de entomologia (ZUCCHI et al. 1993, GALLO et al. 2002, RAFAEL et al. 2012).

Os experimentos sobre os efeitos do pó-debasalto incorporado ao solo no desenvolvimento de plantas de alface e os efeitos da aplicação aérea de pó-de-basalto na dinâmica populacional de insetos ocorreram sob as mesmas condições ambientais.

\section{Análise estatística}

Para ambos os experimentos o delineamento experimental foi em blocos casualizados (DBC) com 10 repetições (canteiros) por tratamento (póde-basalto). Os dados foram submetidos à análise de variância e as médias comparadas pelo teste Tukey $(\mathrm{p} \leq 0,05)$, utilizando o software Genes (CRUZ 2013). 


\section{RESULTADOS E DISCUSSÃO}

$\mathrm{Na}$ análise química do pó-de-basalto das três localidades de Santa Catarina (Belmonte, São Miguel do Oeste, e São José do Cedro) o principal composto químico detectado foi o dióxido de silício (Tabela 1), o qual é um dos compostos químicos encontrados em maior quantidade no pó-de-basalto (COSTA et al. 2006). Este composto químico é considerado o principal responsável pelo maior desenvolvimento radicular e estrutural de plantas (PEREIRA et al. 2012). No presente estudo, mudas de alface cultivadas em canteiros com a presença de pó-de-basalto incorporado ao solo apresentaram um incremento significativo $(\mathrm{p} \leq 0,05)$ na estatura da planta, no crescimento do sistema radicular e na massa seca quando comparadas à testemunha (Tabela 2). Entretanto, não foram observadas diferenças significativas $(\mathrm{p} \leq 0,05)$ no diâmetro do colmo e no volume do sistema radicular $\left(\mathrm{cm}^{3}\right)$ quando as mudas de alface foram submetidas à fertilização com pó-debasalto, independentemente da origem do material (Tabela 2). Da mesma forma, KLEIN et al. (2009) verificaram um maior índice de crescimento e massa seca da parte aérea e crescimento do sistema radicular na cultura do almeirão adubada com pó-de-basalto em cultivo a campo, em relação à testemunha. $\mathrm{O}$ alto desempenho encontrado com a adubação rica em silício, também foi observado na cultura do arroz, sendo que após a aplicação de $350 \mathrm{~kg}$ de silício por hectare foi verificado um maior peso de massa de 1000 sementes e um maior acúmulo de massa seca foliar e massa de matéria seca total na utilização do silicato de cálcio em comparação com o calcário e o tratamento controle (testemunha) (MAUAD et al. 2013).

Além de promover um melhor desempenho anatômico, o silício encontrado no pó-de-basalto proporciona um maior vigor das plantas diminuindo a suscetibilidade ao ataque de patógenos (CANTUÁRIO et al. 2014). Os mecanismos pelos quais o silício pode conferir resistência a doenças podem ser pelo acúmulo do elemento na parede das células da epiderme e cutícula, acúmulo no local de penetração do patógeno (barreiras estruturais), ou ativação das barreiras químicas e bioquímicas da planta (EPSTEIN 1999, CARVALHO-PUPATTO et al. 2004)

Em relação à pigmentação encontrada nas folhas de alface, foi verificado um acréscimo no teor clorofila de 0,054 (SMO), 0,046 (SJC) e 0,034 (BM) $\mathrm{mg} \mathrm{g}^{-1}$ e um maior teor de carotenoides totais 0,046 (SMO), 0,044 (SJC) e 0,034 (BM) $\mathrm{mg} \mathrm{g}^{-1} \mathrm{em}$ plantas fertilizadas com pó-de-basalto, quando comparadas à testemunha (Tabela 3). A menor pigmentação encontrada na folha em plantas que foram adubadas com pó-de-basalto oriundo de Belmonte pode ser justificada pela menor quantia de magnésio presente em sua composição (Tabela 1), deste modo, afetando na formação de novas moléculas de clorofila. $\mathrm{O}$ incremento no teor de clorofila e carotenoides nas folhas de alface nos tratamentos com incorporação de pó-de-basalto no solo pode estar relacionado com a alta concentração de silício disponibilizado no solo (WANG \& GALLETTA 1998). Resultados semelhantes ao presente estudo foram obtidos por LOCARNO et al. (2011) em que verificaram diferenças significativas nos teores de clorofila em folhas de roseira e em morangueiro (BRAGA et al. 2009) após a aplicação de silício no solo. Este fato, aliado com um melhor desempenho radicular das plantas de alface proporcionou uma maior absorção de nutrientes e água do solo aumentando consequentemente os níveis de clorofila e carotenoides.

O aumento do teor de clorofila e carotenoides nos tecidos das plantas proporciona uma maior proteção dos fotossistemas, impedindo consequentemente a foto-oxidação das clorofilas (TAIZ \& ZEIGER 2002). Este fato pode proporcionar uma maior proteção contra a incidência de insetos-pragas e doenças (LIMA et al. 2010), fato observado no presente estudo, em que foi verificada uma redução significativa $(\mathrm{p} \leq 0,05)$ no nível populacional de insetos amostrados após a pulverização com soluções compostas com pó-de-basalto em relação ao tratamento controle (testemunha) (Figura 1).

Durante o período de estudo, as principais espécies de insetos fitófagos amostradas foram Liriomyza sativae (Blanchard, 1938) (Diptera: Agromyzidae), Thrips tabaci Lindeman, 1888 (Thysanoptera: Thripidae), Nezara viridula (Linnaeus, 1758) (Hemiptera: Pentatomidae), Lagria villosa (Fabricius, 1783) (Coleoptera: Tenebrionidae), Diabrotica speciosa (Germar, 1824) (Coleoptera: Chrysomelidae) e Cerotoma arcuata (Olivier, 1791) (Coleoptera: Chrysomelidae). Dentre as espécies encontradas, somente a $L$. sativae é considerada praga-chave na cultura da alface (IMENES et al. 2000). Contudo, com a pulverização sequencial de soluções com pó-de-basalto, houve uma redução de aproximadamente $50 \%$ na incidência de insetos 
Tabela 2. Médias ( \pm EP) de estatura da planta (EP), comprimento do sistema radicular (CSR), diâmetro da inserção (DI), volume (V) e massa seca (MS), de alface cv. Verônica em resposta à aplicação no solo de pó-de-basalto de diferentes origens, coletados nos municípios de São Miguel do Oeste (SMO), São José do Cedro (SJC) e Belmonte (BM), em Santa Catarina.

Table 2. Mean ( $\pm E P$ ) of plant height (EP), root length (CSR), insertion diameter (DI), volume (V) and dry mass (MS), lettuce cv. Veronica in response to soil application of powder-basalt from different sources, collected in the municipalities of São Miguel do Oeste (SMO), São José do Cedro (SJC), and Belmonte (BM), in Santa Catarina state.

\begin{tabular}{lccccc}
\hline Tratamentos & EP $(\mathrm{cm})$ & CSR $(\mathrm{cm})$ & DI $(\mathrm{cm})$ & V $\left(\mathrm{cm}^{3}\right)$ & MS $(\mathrm{g})$ \\
\hline SMO & $29,70 \pm 1,55 \mathrm{a}$ & $19,46 \pm 1,67 \mathrm{a}$ & $5,62 \pm 0,55 \mathrm{a}$ & $3,44 \pm 0,54 \mathrm{a}$ & $1,32 \pm 0,21 \mathrm{a}$ \\
SJC & $28,60 \pm 1,45 \mathrm{a}$ & $18,08 \pm 1,89 \mathrm{a}$ & $5,46 \pm 0,21 \mathrm{a}$ & $3,50 \pm 0,43 \mathrm{a}$ & $1,22 \pm 0,18 \mathrm{a}$ \\
BM & $29,22 \pm 1,65 \mathrm{a}$ & $18,46 \pm 1,75 \mathrm{a}$ & $5,18 \pm 0,89 \mathrm{a}$ & $4,88 \pm 0,28 \mathrm{a}$ & $1,21 \pm 0,54 \mathrm{a}$ \\
Testemunha & $19,82 \pm 1,21 \mathrm{~b}$ & $9,08 \pm 1,08 \mathrm{~b}$ & $5,06 \pm 0,55 \mathrm{a}$ & $2,02 \pm 0,73 \mathrm{a}$ & $0,82 \pm 0,15 \mathrm{~b}$
\end{tabular}

Médias seguidas pela mesma letra minúscula na coluna não diferem estatisticamente entre si pelo teste de Tukey $(\mathrm{p}<0,05)$.

Tabela 3. Teor de clorofila e carotenoides $\left(\mathrm{mg} \mathrm{g}^{-1}\right)$ (médias $\left.\pm \mathrm{EP}\right)$ de folhas de alface em resposta à aplicação de pó-de-basalto de diferentes origens, coletados nos municípios de São Miguel do Oeste (SMO), São José do Cedro (SJC) e Belmonte (BM), em Santa Catarina.

Table 3. Chlorophyll content and carotenoids $\left(\mathrm{mg} \mathrm{g}^{-1}\right)$ (mean $\pm E P$ ) of lettuce leaves in response to the application of basalt powder of different origins, collected in the municipalities of São Miguel do Oeste (SMO), São José do Cedro (SJC), and Belmonte (BM), in Santa Catarina state.

\begin{tabular}{lcccc}
\hline Tratamentos & Clorofila $b$ & Clorofila $a$ & CT & Carotenoides \\
\hline SMO & $0,536 \pm 0,18 \mathrm{a}$ & $0,258 \pm 0,12 \mathrm{a}$ & $0,788 \pm 0,21 \mathrm{a}$ & $0,230 \pm 0,51 \mathrm{a}$ \\
SJC & $0,520 \pm 0,24 \mathrm{a}$ & $0,250 \pm 0,23 \mathrm{a}$ & $0,766 \pm 0,18 \mathrm{a}$ & $0,228 \pm 0,27 \mathrm{a}$ \\
BM & $0,490 \pm 0,21 \mathrm{~b}$ & $0,238 \pm 0,36 \mathrm{~b}$ & $0,732 \pm 0,55 \mathrm{~b}$ & $0,218 \pm 0,36 \mathrm{~b}$ \\
Testemunha & $0,428 \pm 0,23 \mathrm{c}$ & $0,204 \pm 0,22 \mathrm{c}$ & $0,644 \pm 0,33 \mathrm{c}$ & $0,184 \pm 0,45 \mathrm{c}$
\end{tabular}

Médias seguidas pela mesma letra minúscula na coluna não diferem estatisticamente entre si pelo teste de Tukey ( $\mathrm{p} \leq 0,05)$.

quando comparado com a testemunha (Figura 1).

Foram observados picos populacionais de insetos-praga antes de cada pulverização com as soluções de pó-de-basalto ao longo do experimento, ou seja, após pulverização, a população de insetos decrescia, havendo um acréscimo à medida que se aproximava do período da próxima aplicação (Figura 2). Entretanto, no tratamento controle (testemunha) não houve pico populacional, mantendo-se assim, uma constância numérica de insetos capturados ao longo dos dias (Figura 2). Este fato pode estar associado a algum efeito de repelência do composto formulado a partir de pó-de-basalto ou pelo silício contido nele. $\mathrm{O}$ silício encontrado em alguns adubos minerais pode ficar retido na parede celular, estômatos e tricomas, podendo originar depósitos amorfos chamados de fitólitos ou sílica biogênica que atuam como fontes de repelência para os insetos (MITANI \& MA 2005). Da mesma maneira, a baixa incidência de insetos fitófagos nos tratamentos com pó-de-basalto pode estar correlacionada diretamente com a quantidade de silício absorvido pela planta na forma de ácido monosilícico $\left(\mathrm{H}_{4} \mathrm{SiO}_{4}\right)$ (RODRIGUES et al. 2011).

A deposição de sílica na parede da epiderme das células torna a planta mais resistente devido à formação de uma barreira mecânica impedindo o ataque de insetos e/ou pode ocasionar alterações nas suas respostas químicas, aumentando a síntese de toxinas que podem agir como substâncias inibidoras ou repelentes (MITANI \& MA 2005, GOMES et al. 2009, BUSSOLARO et al. 2011, RODRIGUES et al. 2011). 


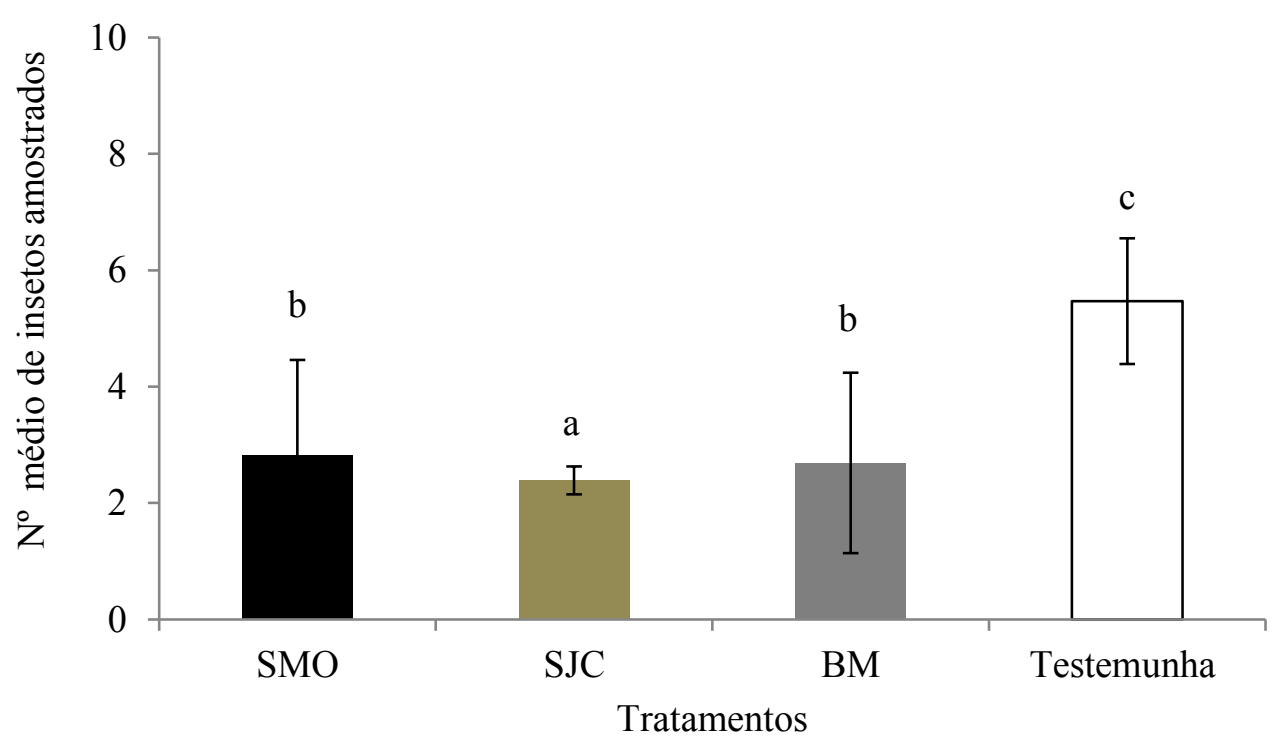

Figura 1. Número médio ( \pm EP) de insetos amostrados em plantas de alface cv. Verônica em resposta à aplicação aérea de pó-de-basalto coletados nos municípios de São Miguel do Oeste (SMO), São José do Cedro (SJC) e Belmonte (BM), em Santa Catarina.

Médias seguidas pelas mesmas letras nas barras não diferem estatisticamente entre si pelo teste Tukey $(\mathrm{p} \leq 0,05)$.

Figure 1. Average $( \pm E P)$ the insects sampled in lettuce plants cv. Veronica in response to the airborne application powder-basalt, collected in the municipalities of São Miguel do Oeste (SMO), São José do Cedro (SJC), and Belmonte (BM), in Santa Catarina state.

Means followed by the same letters in the bars do not differ statistically from each other by the Tukey test $(p \leq 0.05)$.

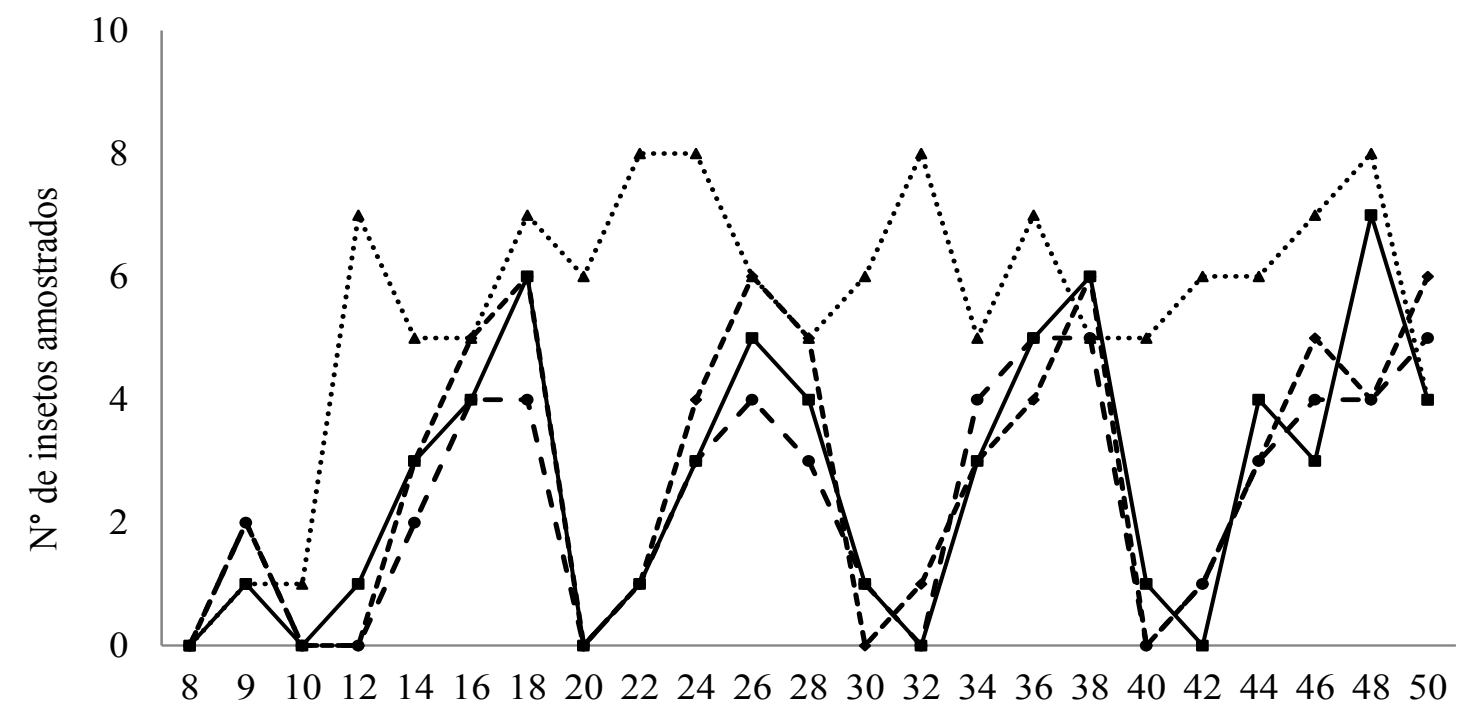

Dias após a aplicação

$$
\text { - Apl. } 1 \text { SJC } \longrightarrow \text { Apl. } 2 \text { BM } \quad-\cdots \text { Apl. } 3 \text { SMO ….... Apl. } 4 \text { Test }
$$

Figura 2. Flutuação populacional de insetos em plantas de alface cv. Verônica em resposta à aplicação via aérea de pó-de-basalto de diferentes origens, coletados nos municípios de São Miguel do Oeste (SMO), São José do Cedro (SJC) e Belmonte (BM), em Santa Catarina.

Figure 2. Population fluctuation of insects in lettuce plants $c v$. Veronica in response to airborne application of powder-basalt from different sources collected in the municipalities of São Miguel do Oeste (SMO), São José do Cedro (SJC), and Belmonte (BM), in Santa Catarina state. 
Além disso, o aumento na deposição da sílica nas paredes das células constitui uma maior barreira mecânica ou promove a indução de síntese de tanino, proporcionando a planta uma maior resistência ao ataque de insetos (YAMADA \& ABDALLA 2006), fato que pode ter ocorrido neste experimento.

\section{CONCLUSÃO}

Diante dos resultados encontrados, sugerese que o pó-de-basalto possa ser um componente para suprir as necessidades minerais dos solos para o cultivo de alface, como também, favorece a diminuição populacional de insetos fitófagos na cultura, auxiliando na proteção contra o ataque de insetos praga. Contudo, não deve ser considerada uma técnica única capaz de controlar os insetos praga, e sim, uma tática que pode ser utilizada no manejo integrado de pragas.

\section{REFERÊNCIAS}

ALMEIDA E et al. 2007. Revitalização dos solos em processos de transição agroecológica no Sul do Brasil. Revista Agriculturas 4: 7-10.

BRAGA FT et al. 2009. Características anatômicas de mudas de morangueiro micropropagadas com diferentes fontes de silício. Pesquisa Agropecuária Brasileira 44: 128132.

BUSSOLARO I et al. 2011. Aplicação de silício no controle de percevejos e produtividade da soja. Cultivando Saber 4: 9-19.

CANTUÁRIO FS et al. 2014. Podridão apical e escaldadura em frutos de pimentão submetidos a estresse hídrico e doses de silício. Horticultura Brasileira 32: 215-219.

CARVALHO-PUPATTO JG et al. 2004. Atributos químicos do solo, crescimento radicular e produtividade do arroz de acordo com a aplicação de escórias. Pesquisa Agropecuária Brasileira 39: 1213-1218.

CQFS-RS/SC. 2004. Comissão de Química e Fertilidade do Solo. Manual de adubação e calagem para os Estados do Rio Grande do Sul e Santa Catarina. 10.ed. Porto Alegre: Sociedade Brasileira de Ciência do Solo. 400p.

COSTA CC et al. 2006. Crescimento, produtividade e qualidade de raízes de rabanete cultivadas sob diferentes fontes e doses de adubos orgânicos. Horticultura Brasileira 24: $118-122$.

CRUZ CD. 2013. GENES: a software package for analysis in experimental statistics and quantitative genetics. Acta Scientiarum. Agronomy 35: 271-276.

EPSTEIN E. 1999. Silicon. Annual Review of Plant Physiology and Plant Molecular Biology 50: 641-664.

ESCOSTEGUY PAV \& KLAMT E. 1998. Basalto moído como fonte de nutrientes. Revista Brasileira de Ciência do Solo 22: 11-20.

GALLO D et al. 2002. Entomologia Agrícola. Piracicaba: FEALQ. 920p.

GOMES FB et al. 2009. Adubação com silício como fator de resistência a insetos-praga e promotor de produtividade em cultura de batata inglesa em sistema orgânico. Ciência e Agrotecnologia 33: 18-23.

GONDIM ARO et al. 2010. Condutividade elétrica na produção e nutrição de alface em sistema de cultivo hidropônico NFT. Bioscience Journal 26: 894-904.

HANISCH AL et al. 2013. Efeito de pó de basalto no solo e em culturas anuais durante quatro safras, em sistema de plantio direto. Revista Brasileira de Agropecuária Sustentável 3: 100-107.

IBGE - Instituto Brasileiro de Geografia e Estatística. 2013. Censo 2014: IBGE Cidades. Disponível em: http://www. ibge.gov.br/cidadesat/topwindow.htm?1. Acesso em: 16 set. 2015.

IMENES SD et al. 2000. Manejo integrado de pragas e doenças na cultura da alface. São Paulo: Secretaria de Agricultura e Abastecimento. 51p. (Manual Técnico. Série Especial, 7).

KLEIN MR et al. 2009. Substratos alternativos para produção de mudas de tomate tipo cereja. Revista Brasileira de Agroecologia 4: 3339-3342.

KORNDÖRFER A et al. 2004. Effect of Calcium Silicate on Feeding and Development of Tropical Sod Webworms (Lepidoptera: Pyralidae). Florida Entomologist 87: 393395.

LAING MD et al. 2006. Silicon use for pest control in agriculture - a review. Proceedings of the South African Sugar Technologists' Association 80: 278-286.

LICHTENTHALER HK \& WELLBURN AR. 1983. Determinations of total carotenoids and chlorophylls a and $\mathrm{b}$ of leaf extracts in different solvents. Biochemical Society Transactions 11: 591-592.

LIMA LM et al. 2010. Quantificação da ferrugem asiática e aspectos nutricionais de soja suprida com silício em solução nutritiva. Summa Phytopathologica 36: 51-56.

LOCARNO $\mathrm{M}$ et al. 2011. Influência da adubação silicatada no teor de clorofila em folhas de roseira. Ciência e Agrotecnologia 35: 287-290.

MAUAD M et al. 2013. Acúmulo de silício na parte aérea de cultivares de arroz de terras altas afetado pela aplicação de silicato e carbonato no solo. Semina: Ciências Agrárias 34: 2049-2060.

MELO VF et al. 2012. Doses de basalto moído nas propriedades químicas de um Latossolo Amarelo distrófico da savana de Roraima. Acta Amazonica 42: 471-476.

MITANI N \& MA JF. 2005. Uptake system of silicon in different plant species. Journal of Experimental Botany 56: 1255-1261.

NOJOSA GBA et al. 2005. Uso de fosfitos e silicatos na indução de resistência. In: CAVALCANTI LS et al. (Eds.). 
Indução de resistência em plantas a patógenos e insetos. Piracicaba: FEALQ. p.139-153.

OSTERROHT MV. 2003. Rochagem Para Que? Revista Agroecologia Hoje 20: 12-15.

PEREIRA DC et al. 2012. Produção de mudas de almeirão e cultivo no campo, em sistema agroecológico. Revista Brasileira de Engenharia Agrícola e Ambiental 16: 11001106.

PRATES FBS et al. 2010. Crescimento de mudas de maracujazeiro-amarelo em resposta à adubação com superfosfato simples e pó de rocha. Revista Ceres 57: 239246.

PRATES FBS et al. 2012. Crescimento de mudas de pinhãomanso em resposta a adubação com superfosfato simples e pó-de-rocha. Revista Ciência Agronômica 43: 207-213.

RAFAEL JA et al. 2012. Insetos do Brasil: Diversidade e Taxonomia. Ribeirão Preto: Editora Holos. 810p.

RESENDE FV et al. 2007. Cultivo de alface em sistema orgânico de produção. Brasília: Embrapa Hortaliças.16p. (Circular Técnica, 56).

RESENDE M et al. 2002. Pedologia base para distinção de ambientes. 4.ed. Viçosa: NEPUT. 338p.

RODRIGUES FA et al. 2011. Silício: um elemento benéfico e importante para as plantas. Informações Agronômicas 134: $14-20$.

SALA FC \& COSTA CP. 2012. Retrospectiva e tendência da alfacicultura brasileira. Horticultura Brasileira 30: 187194.

SILVA A et al. 2012. Avaliação dos efeitos da aplicação de basalto moído na fertilidade do solo e nutrição de Eucalyptus benthamii. Floresta 42: 69-76.

SILVA VF et al. 2010. Influence of silicon on the development, productivity and infestation by insect pests in potato crops. Ciência e Agrotecnologia 34: 1465-1469. TAIZ L \& ZEIGER E. 2002. Fisiologia Vegetal. Porto Alegre: Artmed. 690p.

THEODORO SH et al. 2012. A Importância de uma Rede Tecnológica de Rochagem para a Sustentabilidade em Países Tropicais. Revista Brasileira de Geografia Física 6: 1390-1407.

WANG SY \& GALLETTA GJ. 1998. Foliar application of potassium silicate induces metabolic changes ins strawberry plants. Journal of Plant Nutrition 21: 157-167. WITHAM FH et al. Experiments in plant physiology, Van Nostrand Reinhold. New York, USA. p. 167-200.

YAMADA T \& ABDALLA SRS. 2006. Manejo sustentável na agricultura. Informações Agronômicas, Piracicaba. p. $1-13$.

ZUCCHI RA et al. 1993. Guia de identificação de pragas agrícolas. Piracicaba: FEALQ. 139p. 